\title{
An Investigation of Hypertension Risk Factors among Adults in Oshikoto Region in Namibia
}

\author{
Emilia Shiwa Ashipala ${ }^{1} \&$ Linda Ndeshipandula Lukolo ${ }^{1,2}$ \\ ${ }^{1}$ Namibia Field Epidemiology and Laboratory Training Program, Ministry of Health and Social Services, \\ Windhoek, Namibia \\ ${ }^{2}$ Department of Community and Family medicine, School of Medicine, University of Namibia, Windhoek, \\ Namibia \\ Correspondence: Linda Ndeshipandula Lukolo, Department of Community and Family medicine, School of \\ Medicine, University of Namibia, Windhoek, Namibia.
}

Received: March 10, 2021 Accepted: April 26, 2021 Online Published: June 18, 2021

doi:10.5539/gjhs.v13n7p115 URL: https://doi.org/10.5539/gjhs.v13n7p115

\begin{abstract}
Introduction: Hypertension complications are responsible for 9.4 million deaths worldwide and among these deaths, $51 \%$ are due to stroke and $45 \%$ are due to heart disease like heart failure. This study aims to investigate the hypertension risk factors among adult in Oshikoto region, Namibia.
\end{abstract}

Methods: A community population-based, cross- sectional survey was conducted using WHO STEPwise approach among 375 adults in Oshikoto region. Bivariate and multivariate analysis was done to determine the association between risk factors and Hypertension, based on p-value $<0.05$.

Results: Overall prevalence for risk factors was: physical inactivity (25.3\%), unhealthy diet (75.7\%), tobacco use (9.1\%), harmful use of alcohol (40.8\%). 20.5\% overweight with majority (85.7\%) of them were females. Obesity was $9.1 \%$ in which $91.2 \%$ were females. Hypertension prevalence was $24.3 \%$. Four percent of individuals were having two multiple risk factors for hypertension, $2.4 \%$ with four risk factors and 1.1\% with more than four risk factors. Age group $(\mathrm{OR}=2.48,95 \% \mathrm{CI}=1.44-4.26, \mathrm{P}=0.001)$, Obesity $(\mathrm{OR}=3.48,95 \% \mathrm{CI}=1.55-7.79, \mathrm{P}=0.003)$, and overweight $(\mathrm{OR}=2.34,95 \% \mathrm{CI}=1.31-4.19, \mathrm{P}=0.004)$ were significant risk factors for hypertension.

Conclusions: This study revealed a high prevalence and burden of hypertension risk factors such as obesity and overweight among adults in Oshikoto region, thus, these results highlight the need for interventions to reduce and prevent those risk factors of hypertension in Oshikoto region, Namibia.

Keywords: investigation, hypertension, non-communicable diseases, risk factors, Oshikoto region.

\section{Introduction and Background}

Namibia like other developing countries is experiencing an epidemiological health transition that is characterized by an increasing burden of non-communicable diseases (NCDs). This transition is linked to the high rate of urbanization and development strides that leads to general economic improvement in social and health indicators for the country. At the same time, urbanization has its own consequences including several personal lifestyle habits that ultimately would impact negatively on the health status of the individual. The effect of this is a shift in a spectrum of diseases that were not common in the population to even more dramatic resurgence of many non-communicable diseases (World Health Organization, 2017). NCDs results in more than 40 million deaths every year globally in which 15 million deaths were accounted for people between the ages of 30 and 70 years (Nelson, Nyarko, \& Binka, 2015). Major NCDs such as cardiovascular diseases which include hypertension, cancer, diabetes and chronic respiratory diseases are responsible for $71 \%$ of deaths worldwide (WHO, 2018).

In 2011 nine global targets of NCDs prevention and control were adapted in the United Nation (UN) General Assembly. The aim was to reduce premature mortality from the four major NCDs such as cardiovascular diseases (hypertension), chronic respiratory diseases, cancer and diabetes to $25 \%$ by 2025 . The targets identified were salt intake, tobacco use, harmful alcohol use, obesity, raised blood pressure, raised blood glucose and physical inactivity. In 2015 World Health Organization (WHO) approach to Surveillance of NCDs Risk Factors (STEPS) was established as a global surveillance strategy in a response for trends of NCDs at country-level (WHO, 2017; WHO, 2018). Among targets of the 17 Sustainable Development Goals (SDGs), SDG 3 is to ensure a reduction by 
one third in NCDs (including hypertension) premature mortality by 2030 (IDFA, 2018).

The burden of hypertension among low-income and middle-income countries is increasing disproportionately and almost half of premature deaths occur. However, these deaths are affected those furthest behind and the poorest, because the epidemic of NCDs is driven by poverty, globalization of marketing and trade of health-harming products, rapid urbanization, and population growth. Hypertensions' complications are responsible for 9.4 million deaths worldwide and among these deaths, $51 \%$ are due to stroke and $45 \%$ are due to heart disease like heart failure. The common modifiable behavioral risk factors for hypertension are tobacco use, unhealthy diet, physical inactivity, and the harmful use of alcohol. Their clustering increases significantly the risk of cardiovascular disease morbidity and mortality, and, could lead to overweight and obesity, raised blood pressure, raised cholesterol, and ultimately disease (WHO, 2017; Nelson, Nyarko, \& Binka, 2015; Namibia Statistics Agency (NSA), 2017). These risk factors are preventable and can be completely eliminated (WHO, 2017). According to DHIS2, the prevalence of Hypertension in Oshikoto region was recorded to be $56.8-59.1 \%$ in adults aged 18 years and above with $21.4 \%$ mortality for the region in year 2017 (MoHSS, 2018). Hypertension (Hpt) was indicated in the Health facility-based data as first causes of disability among adults in Namibia (MoHSS, 2018; WHO, 2016). This study was conducted to investigate the hypertension risk factors among adult in Oshikoto region, Namibia.

\section{Methodology}

\subsection{Study Design and Setting}

A quantitative, descriptive, community population-based, cross- sectional survey to investigate the hypertension risk factors among adult population in Oshikoto region, Namibia. The study also determines the association between specific risk factors and a health outcome (hypertension) exists among adult population within Oshikoto region in Namibia. It was conducted between November 2018 and January 2019.

\subsection{Study Population}

This study included adults population, 18 years and older with in Oshikoto region in Namibia. Oshikoto region's 2018 population distribution (for 18 years and older) is 109 478. Individuals less than 18 years and vulnerable people example mental restarted were excluded in the study.

\subsection{Sampling Method}

Stratified cluster random sampling method was employed to select households randomly from each Primary Sampling Units (PSU) and in selected household, all adults (18 years and above) are to be sampled.

\subsection{Sample Size and Criteria}

Sample size was calculated using software Epi Info 7.2 version. The precision level on which the true value of the population estimated was $95 \%$ Confidence interval. The number of subjects in this study was estimated to be 370 individuals. One (1) cluster was used in order to balance considerations of cost, resources and time without compromising the representatives of the sample. In order to achieve the study objectives within limited resources and time, the design effect (DE) of 1 was considered, so, the final sample size (n) was still $370(1 \times 370)$. The average household size for 18 years and above was 2.55 persons, therefore 178 households was approached.

\subsection{Validity and Reliability}

Pilot study was conducted in Oshana region among similar target population prior to actual data collection to assess the feasibility of the study. The interviewer-administered questionnaire was tested and retested to the same individuals from pilot area on different occasions, and then, their responses reviewed for similarities.

\subsection{Data Collection Instruments and Procedure}

A structured questionnaire was used to capture data on demographic and behavioral risk factors; as well as anthropometric (blood pressure, height, weight) and biochemical (blood glucose) measurements. The collection tool was developed and modified based on the WHO STEPwise Approach.

\subsection{Data Analysis Method}

The collected data was entered in computer, cleaned, coded, edited for inconsistencies and then analyzed using Epi Info 7.2 version to: generate frequencies and proportions. WHO guideline for blood pressure was used to classy the blood pressure (BP) results as normal or abnormal. Data was summarized using descriptive statistics and presented as tables, charts and graphs. Chi-square was used to test association and statistical significance has accepted at $\mathrm{p}$-value $<0.05$. Multivariate logistic regression analysis test has performed. 


\subsection{Ethical Considerations}

Ethical approval was obtained from the University of Namibia, the Ministry of Health and Social Services (MoHSS) National Health Research Unit (NHRU) as well as from the Oshikoto regional health Director. The research ethical principles of respect for person, beneficence, justice, and confidentiality were maintained before, during and after the study. Consent was obtained from participants and the nature of the procedure was explained before data collection.

\section{Results}

\subsection{Socio-Demographic Characteristics of the Study Population}

A total number of 375 individuals participated in a study, the majority of participants $279(74.4 \%)$ were female while males were only $96(25.6 \%)$. The mean age of study population was $42.9 \pm 15.0$ years (male respondents: $45.5 \pm 16.2$ years; female respondents: $42.0 \pm 14.5$ years) with representation of participants from all the age groups. Among participants $268(81.6 \%)$ were from age group of $18-55$ years in which majority were age group of 26 - 35 years with $27.2 \%$, while $69(18.4 \%$ ) were 56 and above years of age in which $6.9 \%$ were over 66 years. Most participants $244(65.1 \%)$ were residing in rural area and $100(26.7 \%)$ in urban area and this finding was higher in both males and female. This is presented in Table 1.

Table 1. Socio-demographic characteristics of the study population by sex, Oshikoto region

\begin{tabular}{|c|c|c|c|c|}
\hline Characteristics & Categories & Male (\%) & Female (\%) & Total (\%) \\
\hline \multicolumn{5}{|l|}{ Age in years } \\
\hline & $18-25$ & $7(18.4)$ & $31(81.6)$ & $38(10.2)$ \\
\hline & $26-35$ & $22(21.6)$ & $80(78.4)$ & $102(27.2)$ \\
\hline & $36-45$ & $26(29.2)$ & $63(70.8)$ & $89(23.7)$ \\
\hline & $46-55$ & $18(23.4)$ & $59(76.6)$ & $77(20.5)$ \\
\hline & $56-65$ & $12(27.9)$ & $31(72.1)$ & $43(11.5)$ \\
\hline & $66+$ & $11(42.3) 0$ & $15(57.7)$ & $26(6.9)$ \\
\hline \multicolumn{5}{|l|}{ Residential area } \\
\hline & Rural & $53(21.7)$ & $191(78.3)$ & $244(65.1)$ \\
\hline & Semi - urban & $13(41.9)$ & $18(58.1)$ & $31(8.3)$ \\
\hline & Urban & $30(30.0)$ & $70(70.0)$ & $100(26.7)$ \\
\hline \multicolumn{5}{|c|}{ Level of Education } \\
\hline & Illiterate & $14(45.2)$ & $17(54.8)$ & $31(8.3)$ \\
\hline & Primary education & $26(25.7)$ & $75(74.3)$ & $101(26.9)$ \\
\hline & Secondary education & $48(22.2)$ & $168(77.8)$ & $216(57.6)$ \\
\hline & Tertiary education & $8(29.6)$ & $19(70.4)$ & $27(7.2)$ \\
\hline \multicolumn{5}{|l|}{ Marital status } \\
\hline & Cohabiting & $13(52.0)$ & $12(48)$ & $25(6.7)$ \\
\hline & Divorced & $0(0)$ & $4(100)$ & $4(1.1)$ \\
\hline & Married & $44(37.0)$ & $75(63.0)$ & $119(31.7)$ \\
\hline & Separated & $0(0)$ & $1(100)$ & $1(0.3)$ \\
\hline & Single & $39(18.7)$ & $170(81.3)$ & $209(55.7)$ \\
\hline & Widowed & $0(0)$ & $17(100)$ & $17(4.5)$ \\
\hline \multicolumn{5}{|l|}{ Ethnic group } \\
\hline & Caprivian & $8(61.5)$ & $5(38.5)$ & $13(3.5)$ \\
\hline & Herero/Himba & $5(33.3)$ & $10(66.7)$ & $15(4.0)$ \\
\hline & Kavango & $2(50.0)$ & $2(50.0)$ & $4(1.10$ \\
\hline & Nama/Damara & $4(44.4)$ & $5(55.6)$ & $9(2.4)$ \\
\hline
\end{tabular}




\begin{tabular}{|c|c|c|c|c|}
\hline & San community & $6(30.0)$ & $14(70.0)$ & $20(5.3)$ \\
\hline & Wambo & $73(23.2)$ & $241(76.8)$ & $314(83.7)$ \\
\hline \multicolumn{5}{|l|}{ Employment status } \\
\hline & Government employed & $16(42.1)$ & $22(57.9)$ & $38(10.1)$ \\
\hline & Non-government employed & $20(35.1)$ & $37(64.9)$ & $57(15.2)$ \\
\hline & Pensioner & $19(36.5)$ & $33(63.5)$ & $52(13.9)$ \\
\hline & Self employed & $15(26.3)$ & $42(73.7)$ & $57(15.2)$ \\
\hline & Student & $2(50)$. & $2(50.0)$ & $4(1.1)$ \\
\hline & Unemployed & $24(14.4)$ & $143(85.6)$ & $167(44.5)$ \\
\hline
\end{tabular}

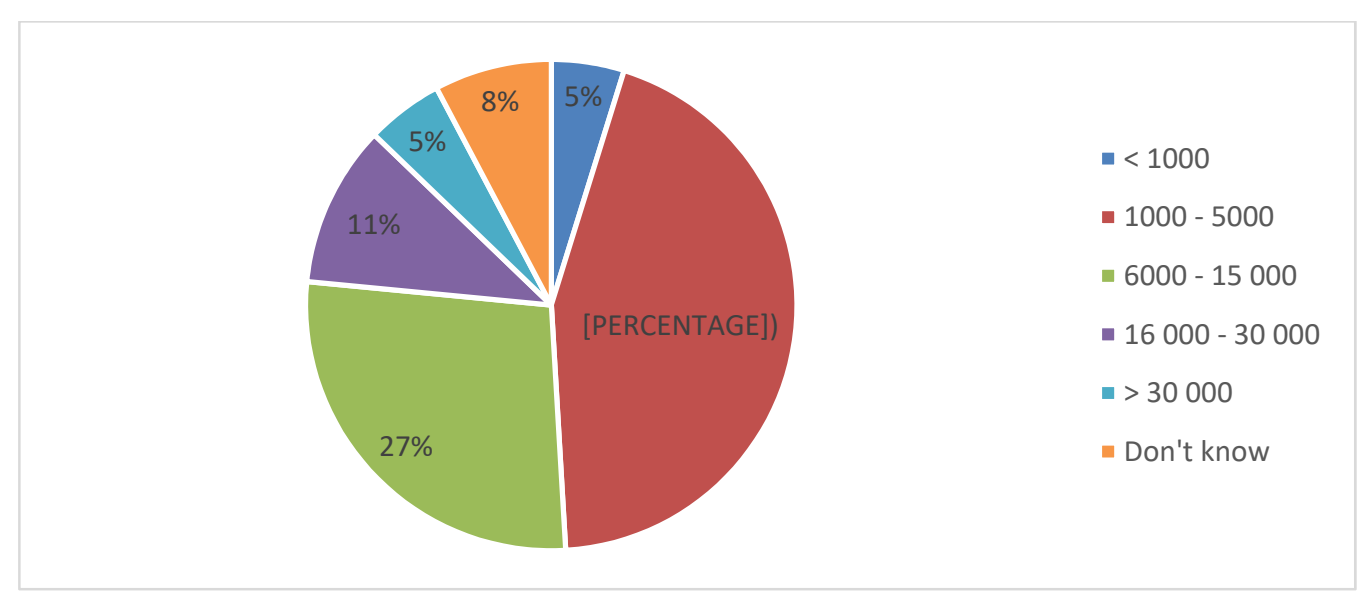

Figure 1. Proportion of participants by monthly average household earning in Namibia dollar (N\$), Oshikoto region

Forty-nine percent of the participants had a monthly average household earning of less than N\$ 6000 and only 19 $(5.1 \%)$ had more than 30000 . Therefore, majority of the participants belongs to lower socio-economic status (Figure 1 above).

\subsection{Behavioral Risk Factors of the Study Population}

Table 2 presents behavioral risk factors for males and females in the study. Among 375 study participants 278 (74.1\%) reported performing physical activity of more than 30 minutes daily, in which $78.4 \%$ were females and 60 (21.6\%) were males. Most 95 (25.3\%) participants were not performing physical activity. Few 56 (14.9\%) were being sedentary as estimated by the duration of time spend reclining or sitting on a typical week and it was found higher among males $26(27.1 \%)(n=96)$ than females $30(10.5 \%)(n=279)$. Walking as a measure for physical activity was a better habit among participants, with majority $319(85.1 \%)$ walking at least 10 hours/ more per week (Table 2). However, 68 (18.1\%) of participants (60.3\% females and 39.7\% males) were not even walking daily for 10 minutes as recommended by WHO, this was found higher (55.5\%) among age groups between 18 and 45 years and majority $48(70.6 \%)$ were living in urban areas.

Among study participants, none of the 183 (48.8\%) consumes any fruit per week (females $75.4 \% \%$ and males $24.6 \%)$. However, 186 (49.6\%) participants consume vegetables at least once a week (females $138(74.2 \%)$ and males $48(25.8 \%)$ ). All participants 375 had salt intake. Most of participants $332(88.5 \%)$ responded that they only ate processed food with high salt and $165(44.0 \%)$ were eating food that not prepared at home in past 14 days. On other hand, vegetable oil was used by majority $362(96.5 \%)$ as type of kitchen oil. This data is presented in Table 2.

About 30 (8\%) of participants reported being current smokers, and this was found higher in men than in women 16 $(53.3 \%)$ and $14(46.7 \%)$ respectively, and it was distributed equally among rural and urban males. Alcohol consumption rate when relates to current use was $132(35.2 \%)$ more among females $80(60.6 \%)$ compared to males $52(39.4 \%)$ and among all 132 participants $90.1 \%$ were accustomed to home brews (Tombo and Katokele) as well as beer (Table 2). 
Table 2. Frequency distribution of the behavioral risk factors for hypertension of study participants by sex, Oshikoto region

\begin{tabular}{|c|c|c|c|c|}
\hline Variables & Categories & Male (\%) & Female (\%) & Total (\%) \\
\hline \multicolumn{5}{|c|}{ Frequency of physical activity per day in minutes } \\
\hline & 0 minutes & $35(36.8)$ & $60(63.2)$ & $95(25.3)$ \\
\hline & $10-30$ minutes & $1(50.0)$ & $1(50.0)$ & $2(0.5)$ \\
\hline & $>30$ minutes & $60(21.6)$ & $218(78.4)$ & $278(74.1)$ \\
\hline \multicolumn{5}{|c|}{ Frequency of sedentary lifestyle per week in hours } \\
\hline & 0 hours/week & $70(21.9)$ & $249(78.1)$ & $319(85.1)$ \\
\hline & $>10$ hours/week & $26(46.4)$ & $30(53.6)$ & $56(14.9)$ \\
\hline \multicolumn{5}{|c|}{ Frequency of walking per day/ week in hours } \\
\hline & 0 hours/week & $20(43.5)$ & $26(56.5)$ & $46(12.3)$ \\
\hline & $>10$ hours/week & $76(23.1)$ & $253(76.9)$ & $329(87.7)$ \\
\hline \multicolumn{5}{|c|}{ Frequency of taking fruits per week } \\
\hline & Zero a week & $45(24.6)$ & $138(75.4)$ & $183(48.8)$ \\
\hline & Once a week & $23(26.7)$ & $63(73.3)$ & $86(22.9)$ \\
\hline & Twice a week & $18(27.7)$ & $47(72.3)$ & $65(17.9)$ \\
\hline & Thrice a week & $6(20.7)$ & $23(79.3)$ & $29(7.8)$ \\
\hline & $>$ three times a week & $4(33.3)$ & $8(66.7)$ & $12(3.2)$ \\
\hline \multicolumn{5}{|c|}{ Frequency of taking vegetables per week } \\
\hline & Zero a week & $44(25.4)$ & $129(74.6)$ & $173(46.1)$ \\
\hline & Once a week & $48(25.8)$ & $138(74.2)$ & $186(49.6)$ \\
\hline & Twice a week & $4(25.0)$ & $12(75.0)$ & $16(4.3)$ \\
\hline \multicolumn{5}{|c|}{ Frequency of salt consumption } \\
\hline & Always & $96(25.6)$ & $279(74.4)$ & $375(100)$ \\
\hline \multicolumn{5}{|c|}{ Frequency of eating processed food high in salt } \\
\hline & Always & $0(0.0)$ & $1(100)$ & $1(0.3)$ \\
\hline & Often & $4(44.4)$ & $5(55.6)$ & $9(2.4)$ \\
\hline & Sometimes & $81(24.4)$ & $251(75.6)$ & $332(88.5)$ \\
\hline & Never & $11(33.3)$ & $22(66.7)$ & $33(8.8)$ \\
\hline \multicolumn{5}{|c|}{ Frequency of eating food that not prepared at home past 14 days } \\
\hline & Yes & $60(36.4)$ & $105(63.6)$ & $165(44.0)$ \\
\hline & No & $36(17.1)$ & $174(82.9)$ & $210(56.0)$ \\
\hline \multicolumn{5}{|c|}{ Type of kitchen oil } \\
\hline & Animal fat & $2(22.2)$ & $7(77.8)$ & $9(2.4)$ \\
\hline & Butter/margarine & $1(33.3)$ & $2(66.7)$ & $3(0.8)$ \\
\hline & Traditional marura oil & $1(100)$ & $0(0.0)$ & $1(0.3)$ \\
\hline & Vegetable oil & $92(25.4)$ & $270(74.6)$ & $362(96.5)$ \\
\hline \multicolumn{5}{|c|}{ Tobacco use } \\
\hline & Current smoker & $16(53.3)$ & $14(46.7)$ & $30(8.0)$ \\
\hline & Never smoker & $77(22.6)$ & $264(70.4)$ & $341(90.9)$ \\
\hline & Previous smoker & $3(75.0)$ & $1(25.0)$ & $4(1.1)$ \\
\hline \multicolumn{5}{|c|}{ Alcohol consumption } \\
\hline & Current use & $52(39.4)$ & $80(60.6)$ & $132(35.2)$ \\
\hline & Never use & $35(15.8)$ & $187(84.2)$ & $222(59.2)$ \\
\hline & Previous use & $9(42.9)$ & $12(57.1)$ & $21(5.6)$ \\
\hline
\end{tabular}




\subsection{Hypertension Biological Risk Factors of the Study Population: Anthropometric and Biochemical Measurements}

These measurements including height, weight, body mass index (BMI can be calculated as ratio of weight $(\mathrm{kg})$ and height square (m), blood pressure, heart rate (Anthropometric) and blood glucose (levels). Mean height for males was $168 \pm 9.3 \mathrm{SD}$ and range between $130-185 \mathrm{~cm}$, while mean height for females was $16 \pm 8.7 \mathrm{SD}$ and range on average males were $168 \mathrm{~cm}$ tall while females were $161 \mathrm{~cm}$ tall. Considering their weight, on average females had $62 \mathrm{~kg}$ as compared to $61 \mathrm{~kg}$ for males. Among all study participants $111(29.6 \%)$ had higher BMI (females $87.4 \%$, male $12.6 \%$ ) with mean (BMI) of $23.3 \pm 4.5 \mathrm{SD}$ and range between 14.0 and 46.0. Females had relatively higher BMI than males (Females $=46$, Males $=36$ ).

Among participants with high blood pressure, proportion of 39 (44.8\%) were currently on hypertension treatment. All participants had their heart rate checked and recorded in which $4(10.9 \%)$ were having abnormal heart rate (bradycardia $=3(7.3 \%)$, tachycardia $=38(92.7 \%)$ ) and it was found higher among female than male with $71.7 \%$ and $29.3 \%$ respectively. Among all study participants 375, 77 (20.5\%) were overweight and $34(9.1 \%)$ were obese. The most affected population per sex was females with $193(78.8 \%)$.

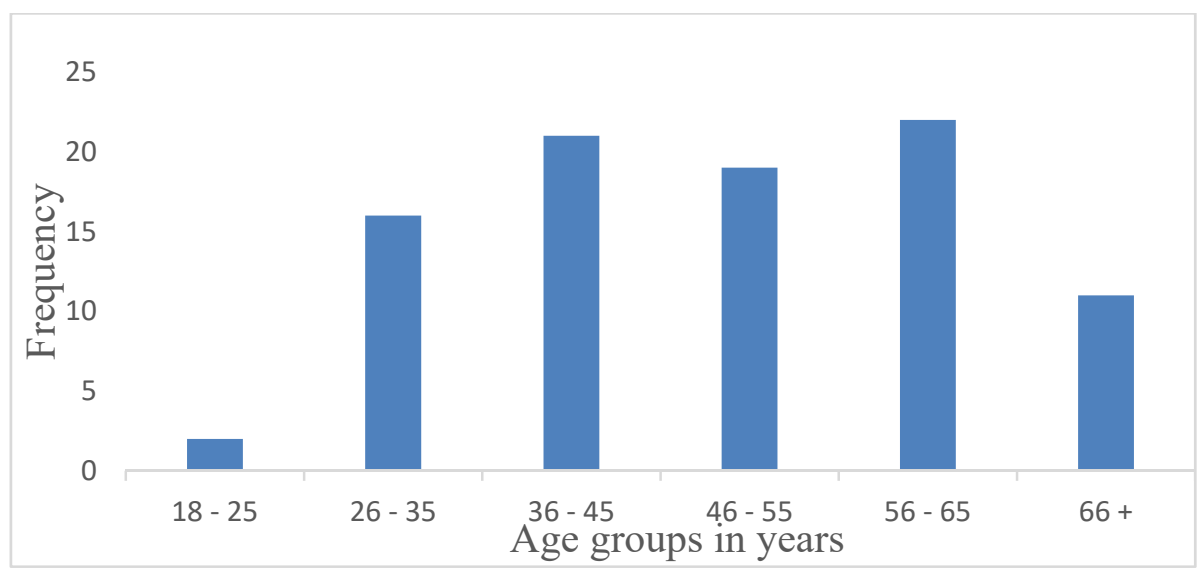

Figure 2. Prevalence of Hypertension by aged group in years, Oshikoto region, 2018

Among all study population 91 (24.3\%) were hypertensive predominantly among age-group 56 - 65 years (22 $(24.2 \%))$, followed by $36-45$ and $46-55$ years with $21(23.1 \%)$ and $19(20.9 \%)$ respectively while $18-25$ years was least with less than three percent (Figure 2). More females 64 (70.3\%) were affected compare to males 27 (29.7\%). Note with 43 (47.3\%) were already on treatment. According to high blood pressure classifications, hypertension was the highest at $57(62.6 \%)$ while almost ten percent $(9.9 \%)$ were found with stage 11 hypertension. In addition, $16(4.3 \%)$ of study participants had two combination risk factor of hypertension such as physical inactivity and unhealthy diet. However, 9 (2.4\%) participants were having both four behavioral risk factors, while $4(1.1 \%)$ were having combination of both behavioral risk factors plus one biological risk factor.

\subsection{Association between Risk Factors and Hypertension}

Two by two analysis results to determine the association between major socio-demographic and risk factors and hypertension are presented in Tables 3. Logistic regression was used to estimate the strength of association for all exposure variables that were statistically significant in bivariate analysis. Results for multivariate logistic regression analysis are presented in Table 4. 
Table 3. Bivariate analysis of hypertension exposure variables among adults in Oshikoto region

\begin{tabular}{|c|c|c|c|c|c|}
\hline \multirow[t]{2}{*}{ Exposure variables } & \multicolumn{2}{|c|}{ Hypertension } & \multirow[t]{2}{*}{ OR } & \multirow[t]{2}{*}{$95 \%$ CI } & \multirow[t]{2}{*}{ P-value } \\
\hline & $\underline{\text { Yes }}$ & No & & & \\
\hline Sex & 27 & 69 & & & \\
\hline Male & 64 & 215 & & & \\
\hline Female & & & 1.31 & $0.78-2.22$ & 0.33 \\
\hline \multicolumn{6}{|l|}{ Age Group (years) } \\
\hline $18-45$ & 39 & 190 & & & \\
\hline $46+$ & 52 & 94 & 0.37 & $0.23-0.60$ & $0.000^{*}$ \\
\hline \multicolumn{6}{|l|}{ Residential area } \\
\hline Rural & 55 & 189 & & & \\
\hline Urban & 36 & 95 & 0.77 & $0.47-1.25$ & 0.31 \\
\hline \multicolumn{6}{|l|}{ Level of Education } \\
\hline Illiterate & 10 & 21 & & & \\
\hline Literate & 81 & 263 & 1.55 & $0.69-3.42$ & 0.28 \\
\hline \multicolumn{6}{|l|}{ Marital status } \\
\hline Married & 46 & 98 & & & \\
\hline Single & 45 & 186 & 1.94 & $1.20-3.13$ & $0.009^{*}$ \\
\hline \multicolumn{6}{|l|}{ Ethnic group } \\
\hline Wambo & 73 & 242 & & & \\
\hline Others & 18 & 42 & 0.7 & $0.38-1.297$ & 0.25 \\
\hline \multicolumn{6}{|l|}{ Employment status } \\
\hline Employed & 39 & 113 & & & \\
\hline Unemployed & 52 & 171 & 1.14 & $0.70-1.83$ & 0.62 \\
\hline Physical Inactivity & 24 & 53 & & & \\
\hline Yes & 67 & 231 & & & \\
\hline No & & & 1.56 & $0.89-2.72$ & 0.14 \\
\hline \multicolumn{6}{|l|}{ Unhealthy Diet } \\
\hline Yes & 36 & 129 & & & \\
\hline No & 55 & 155 & 0.79 & $0.46-0.27$ & 0.34 \\
\hline \multicolumn{6}{|l|}{ Tobacco use } \\
\hline Yes & 9 & 21 & & & \\
\hline No & 82 & 263 & 1.37 & $0.61-3.12$ & 0.51 \\
\hline \multicolumn{6}{|l|}{ Alcohol use } \\
\hline Yes & 37 & 116 & & & \\
\hline No & 54 & 168 & 0.99 & $0.13-1.60$ & 1 \\
\hline \multicolumn{6}{|l|}{ Overweight } \\
\hline Yes & 29 & 52 & & & \\
\hline No & 62 & 232 & 2.09 & $1.22-3.56$ & $0.008^{*}$ \\
\hline \multicolumn{6}{|l|}{ Obesity } \\
\hline Yes & 15 & 19 & & & \\
\hline No & 76 & 265 & 2.75 & $1.34-5.67$ & $0.01 *$ \\
\hline \multicolumn{6}{|l|}{ High blood glucose } \\
\hline Yes & 4 & 2 & & & \\
\hline No & 87 & 282 & 6.48 & $1.17-35.9$ & $0.03 *$ \\
\hline
\end{tabular}

Values in bold and * are statistically significant at $\mathrm{P}$-value $<0.0595 \%$ Confidence Interval, OR=Odds Ratio. 
There was no significant association between sex and hypertension $(\mathrm{OR}=1.31,95 \% \mathrm{CI}=0.78-2.22, \mathrm{P}$-value $=0.33)$. The odds of developing hypertension were 0.37 times more in participants of age group $46+$ than those in 18-45 age group $(\mathrm{OR}=0.37,95 \% \mathrm{CI}=0.23-0.60, \mathrm{P}$-value $=0.000 *)$. Furthermore, hypertension was associated with marital status $(\mathrm{OR}=1.94,95 \% \mathrm{CI}=1.20-3.13$, $\mathrm{P}$-value $=0.009)$; Overweight $(\mathrm{OR}=2.09,95 \% \mathrm{CI}=1.22-3.56$, $\mathrm{P}$-value $=0.008)$; obesity $(\mathrm{OR}=2.75,95 \% \mathrm{CI}=1.34-5.67, \mathrm{P}$-value $=0.01)$; and, high blood glucose $(\mathrm{OR}=6.48$, $95 \% \mathrm{CI}=1.17-35.9$, P-value $=0.03$ ). The other exposure variables were not found to be statistically significant (Table 3).

\subsection{Multivariate Logistic Regression Analysis of Risk Factors Associated with Hypertension}

In order to find independent associations and confounder, multivariate logistic regression analysis was performed for common risk factors that were statistical significant in bivariate analysis versus outcome variables such as hypertension as reflected in Table 4.

Table 4. Multivariate analysis risk factors associated hypertension among adult, Oshikoto region

\begin{tabular}{llll}
\hline Variables & AOR & $\mathbf{0 . 9 5}$ - C.I. & P-Value \\
\hline Age Group (46+/18 - 45) & 2.48 & $1.44-4.26$ & $0.001^{*}$ \\
Marital status (Yes/No) & 1.26 & $0.73-2.17$ & 0.39 \\
Overweight (Yes/No) & 2.34 & $1.31-4.19$ & $0.004^{*}$ \\
Obesity (Yes/No) & 3.48 & $1.55-7.79$ & $0.003^{*}$ \\
Presence of Elevated blood Glucose (Yes/No) & 4.44 & $0.67-29.26$ & 0.12 \\
\hline
\end{tabular}

Values in bold and * are statistically significant at $\mathrm{P}$-value $<0.0595 \%$ Confidence Interval, AOR=Adjusted Odds Ratio. Age group $\left(\mathrm{AOR}=2.48,95 \% \mathrm{CI}=1.44-4.26, \mathrm{P}\right.$-value=0.001*), obesity $\left(\mathrm{AOR}=3.48,95 \% \mathrm{CI}=1.55-7.79, \mathrm{P}-\mathrm{value}=0.003^{*}\right)$ and overweight $\left(\mathrm{AOR}=2.34,95 \% \mathrm{CI}=1.31-4.19, \mathrm{P}\right.$-value $\left.=0.004^{*}\right)$ were found to be significantly association with hypertension, therefore, older age, overweight and obesity were factors that strongly associated with hypertension.

\section{Discussion}

The risk factors of today are the diseases of tomorrow and, the public health interventions/ strategies addressing hypertension risk factors in population should be informed by accurate and reliable data from different settings. This WHO STEPS survey has great importance on providing valuable baseline information needed to develop policies, strategies and plan of action against those risk factors. This study addressed common NCDs risk factors such as physical inactive, unhealthy diet, tobacco use, alcohol consumption (behavioral risk factors); obesity, overweight, blood pressure and random blood glucose (biological risk factors). Majority (74.4\%) of our study participants were females. This is probably because females are mostly confined at home as housewives. This finding is almost the same with the studies conducted in Afghanistan (66.5\%), Zimbabwe (75\%) and Malawi (67.5\%) (IDFA, 2018; Ministry of Health \& WHO, 2010). According to our findings, more participants are from middle age group (26-35 years). This finding is similar to study that was conducted in Uganda (Mondo, Otim, Akol, Musoke \& Orem, 2013). By rural - urban stratification, most of the participants were residing in rural areas than in urban areas, $84 \%$ of Oshikoto region is rural and only $16 \%$ urban (Wu et al., 2015). Studies that were conducted in some of Sub-Saharan African countries, Afghanistan, and India also shared same findings as our study. This study findings could be also due to the fact that most of urban residents are at work during the day than those are residing in rural areas (Saeed, 2013). There was high unemployment rate among participants (aged 26 45 years). Namibia is ranked at second position in Africa with $33.4 \%(19.5-37.6 \%)$ by December 2018 , (MoHSS \& NSA, 2014). Therefore, this high unemployment rate could be associated with the current high unemployment rate in the country at the time of the study.

The main behavioral risk factors for hypertension are physical inactivity, unhealthy diet, obesity, tobacco use and harmful use of alcohol. Individuals are predisposed to NCDs by poverty, unhealthy dietary practice (including low fruits and vegetables intake) and harmful use of alcohol. But on the other hand, as individuals (at household level) become financially stable, their lifestyle changes and then their exposure to NCDs increases and this is because higher incomes promote risky behaviors like higher level of physical inactivity, smoking and consumption of processed foods with high salt/ fat content including Westernization of dietary habits (Omoleke, 2013; Adebamowo, 2011). And this was proven by a study that was conducted in Kenya which found out a $5.42 \%$ association between living in urban setting and NCDs (Adebamowo, 2011). 
Physical inactivity is the fourth leading risk factor for mortality, causing more than 3.2 million deaths global (Mondo, Otim, Akol, Musoke \& Orem, 2013), Physical inactivity among study participants was $25.3 \%$ and this was highest among those residing in urban areas than rural areas and majority were females. These results are almost similar to the overall WHO African regions figures (22\%) and less than global data (28\%) for year 2016 (WHO, 2017; MoHSS \& NSA, 2014). The physical and social environment such as industrialization, urbanization and economic development, social norms and motorized transport are the factors that contribute to physical inactivity (WHO, 2017).

This study found out that majority of the study participants consumed inadequate amount of fruit and vegetables, (almost half do not consume any fruit per week) and about half participants consume vegetables at least once a week with high female respondents. Globally, 2.7 million deaths are attributable to diets low in fruits and vegetables (WHO, 2018). All the study participants were always adding salt in their meals. This finding was almost similar to study conducted in Bangladesh with $80 \%$ of study participants were added salt in their meals (Khalequzzaman et al., 2017). Most participants responded that they ate processed food high in salt sometimes and less than half ate food not prepared at home within past 14 days. Any food that rich in salt (sodium), calories and saturated fats is unhealthy (WHO, 2017). Study conducted in Ethiopia found that 60402 deaths of NCDs were associated with dietary risks (Melaku et al., 2016).

About $8 \%$ of participants reported being current smokers and higher in males than females, and was equally distributed equally among rural and urban males. Unsimilar findings with study conducted in India in 2013 found high prevalence of tobacco use among rural men than urban men (Sajeev \& Soman, 2018). Various study indicated that tobacco smokers have relative risk of 2-3 times higher for coronary heart disease (CHD), 12 time risks for lung cancer, 1.5 times for stroke and 1.4 times for chronic obstructive pulmonary disease (COPD) (WHO, 2017). According to study results, current alcohol consumption rate was less than $50 \%$ and more among females than males. These results might be due to females predominantly in study. However, Studies in other countries found high proportion of alcohol consumption among males (WHO, 2018; Sajeev \& Soman, 2018).

The results from this regional population-based study found gender differences in the prevalence of the measurements. On the average height of study population, males were taller than females. Findings also shows high body mass index (BMI) in females than males. However, study conducted in Lebanon does not support this (Khalequzzaman et al., 2017). The substantial proportion of population was overweight, found higher among females compared to males. Study finding is congruous with previously published studies and this established a warning sign that need urgently consideration before reaching drastic levels (Saeed, 2013; Kavishe et al., 2015). In addition, the prevalence of obesity based on BMI of $\geq 30$ was higher in females than males. This was attributed by the physical inactivity, unhealthy diet (caloric intake) and sedentary lifestyle especially among urban residents. These result was similar to findings of a study conducted in sub-Saharan Africa countries reported that increasing rise of overweight and obesity was associated with genetic, physical inactivity and caloric intake and other underlying causes such as globalization, urbanization, occupation and perceptions of weight in some cultures (WHO, 2017 \& Adebamowo, 2011). Previous published studies have demonstrated that changing lifestyle could prevent overweight and obesity, which in long run prevent NCDs such as hypertension in selected adult groups at high risk (MoHSS \& NSA, 2014; Saeed, 2013; Adebamowo, 2011; Khalequzzaman et al., 2017).

This study found higher prevalence of high blood pressure among females and many were undiagnosed. Approximately quota of adult population (18 and above) in Oshikoto region has hypertension with almost half currently on treatment and majority were females. Most participants on hypertension treatment BP was not controlled. Results of an Afghanistan and Iranian study support these findings, in which the overall prevalence rate of hypertension was $27.1 \%$, however, this study reported higher prevalence of hypertension in males than females (Saeed, 2013). Hypertension is more among older age groups even though less proportion of participants under 25 years of age has hypertension. This finding was similar to studies done in Tanzania and Uganda (WHO, 2017; Kavishe et al., 2015). This study found about ten percent of study population has abnormal heart rate, with higher proportion of tachycardia. Study conducted in Tanzania had support this findings (Kavishe et al., 2015).

Our study found some study participants with two or more combination risk factor of hypertension in which majority were urban residents. This finding was similar to study conducted in Afghanistan which reported that participants residing in urban areas were more likely to have two or more risk factors than those in rural areas. This also concur with other study cited in Saeed, 2013 found urban residence as primary risk factor for NCDs impacting the health of population. Therefore, these findings suggested that the interventions are needed to target a group of risk factors and the control strategy to address urbanization and warrants gender-sensitive strategies specifically aiming women. The bivariate analysis among socio-demographic variables of our study revealed that the age, 
marital status, overweight, obesity and raised blood glucose were independently associated with hypertension.

The prevalence of hypertension significantly increased with age when comparing those $\geq 46$ years old with those $\leq 45$ years old. With being married compared with those single, hypertension prevalence was significantly high among married participants. Furthermore, this study reveals the odds of being hypertensive increased by existence of overweight and obesity. Other published studies conducted in Afghanistan, Angola, China, Tanzania and Uganda were in agreements with these findings that older age and higher BMI were significantly associated with hypertension (Saeed, 2013; Mondo et al., 2013; Khalequzzaman et al., 2017; Kavishe et al., 2015). This study results shows that in order to managing hypertension, it needs comorbidity consideration, therefore, this study suggests the screening program to be established to prevent the development of hypertension. The multivariate logistic regression analysis of these study findings clearly listed out older age, overweight and obesity as leading risk factors for hypertension. This finding was narrated to other studies especially association between older age and obesity, however, those studies have other risk factor which were found with strongly significant like education and alcohol consumption (Saeed, 2013; Sajeev, 2018). Therefore, the intervention at population level should target a group of risk factors in order to reduce the growing burden of hypertension.

\section{Conclusion}

This study revealed a high prevalence and burden of hypertension risk factors among adult in Oshikoto region, directing to changing disease epidemiology of hypertension. The researcher concluded that this increased in the burden of these risk factors could be due to rapid growth of urbanization in Oshikoto region that responsible for lifestyle changes and this was likely to inflict a major public health in future. Finally, researcher's conclusion absolutely assumed that the risk factors measured influence hypertension risk in Namibian population as they do in other SSA, Asia and European population where most studies have been conducted. Therefore, our findings can serve as baseline epidemiological data which aid policymakers to develop suitable hypertension control strategies.

\section{Acknowledgements}

The authors would like to thank the research participants who volunteered to participate in the survey, the University of Namibia and the Ministry of Health and Social service at large for allowing the study to be conducted. The authors are grateful to Epidemiology department, Ministry of Health and Oshikoto Regional Health Management Team for logistic support, as well as the Namibia Statistic Agency for statistical support.

\section{Competing Interests Statement}

The authors declare there is no conflict of interest in this study. The study was self-funded by the authors.

\section{References}

Adebamowo, C. (2011). Non- Communicable Diseases in Sub-Saharan Africa: What we know now. International Journal of Epidemiology, 40, 885-901. https://doi.org/10.1093/ije/dyr050

International Diabetes FederationAfrica [IDFA]. (2018). www.idf.orga

Kavishe B, et al. (2015). High prevalence of hypertension and of risk factors for non-communicable diseases (NCDs): a population based Cross-Sectional Survey of NCDs and HIV infection in Northwestern Tanzania and Southern Uganda. BMC Medicine, 13, 126. https://doi.org/10.1186/s12916-015-0357-9

Khalequzzaman, M., et al. (2017). Prevalence of non-communicable disease risk factors among poor shantytown residents in Dhaka, Bangladesh: a community-based cross-sectional survey. BMJ Open, 7. https://doi.org/10.1136/bmjopen-2016-014710

Melaku et al. (2016). The impact of dietary risk factors on the burden of non-communicable diseases in Ethiopia: findings from the Global Burden of Disease study 2013. International Journal of Behavioral Nutrition and Physical Activity, 13, 122. https://doi.org/10.1186/s12966-016-0447-X

Minicuci, N., Salinas-Rodriguez, A., Manrique-Espinoza, B., Maximova, T., Peltzer, K., Phaswanamafuya, N., ... \& Kowa, P. (2015). Common risk factors for chronic non-communicable diseases among older adults in China, Mexico, India, Russia and South Africa: the study on global AGEing and adult health (SAGE) wave 1. BMC Public Health, 15(88). https://doi.org/10.1186/s12889-015-1407-0

Ministry of Health and Social Services. (2018). DHIS2. https://doi.org/10.15406/ncoaj.2017.02.00026

Ministry of Health and Social Services \& Namibia statistics Agency. (2014). Namibia Demographic and Health Survey 2013. Windhoek, Namibia.

Ministry of Health \& World Health Organization. (2010). Malawi National STEPS Survey for Chronic 
Non-Communicable Diseases and their Risk Factors. Lilongwe 3; Malawi.

Mondo, C. K., Otim, M. A., Akol, G., Musoke, R., \& Orem, J. (2012). The prevalence and distribution of non-communicable diseases and their risk factors in Kasese district, Uganda. Cardiovascular Journal of Africa, 24(3), 52-57. https://doi.org/10.5830/CVJA-2012-081

Namibia Statistics Agency. (2017). Namibia Inter - Censual Demographic Survey 2016 Report, Windhoek, Namibia.

Nelson, F., Nyarko, K. M., \& Binka, F. N. (2015). Prevalence of Risk Factors for Non-communicable Diseases for New Patients Reporting to Korle-Bu Teaching Hospital. Ghana medical Journal, 49(1) https://doi.org/10.4314/gmj.v49i1.3

Omoleke, S. O. (2013). Chronic Non- Communicable Diseases as a New Epidemic in Africa: Focus on the Gambia. Pan African Medical Journal, 14(87), 603. https://doi.org/10.11604/pamj.2013.14.87.1899

Saeed, K. M. I. (2013). Prevalence of Risk Factors for Non-Communicable Diseases in the Adult Population of Urban Area in Kabul City, Afghanistan. Central Asian Journal of Global Health, 2, 2. https://doi.org/10.5195/CAJGH.2013.69

Sajeev, P., \& Soman, B. (2018). Prevalence of Non-Communicable Diseases risk factors among the Kani tribe in Thiruvananthapuram district, Kerala. Indian Heart Journal, $70,598$. https://doi.org/10.1016/j.ihj.2018.01.022

World Health Organization. (2018). Analytical summary. Geneva.

World Health Organization. (2018). Non-communicable Diseases (NCDs) Country Profiles.

World Health Organization. (2017). Non-communicable Disease Progress Monitor 2017.

World Health Organization. (2017). Risk Factor. Geneva. Retrieved from http://www.who.int/topics/risk_factors/en//

World Health Organization Africa. (2016). Atlas of African Health Statistics: Health Situation Analysis of the African Region. African Health Observatory, WHO: Cite du Djoue, Brazzaville, Congo.

\section{Copyrights}

Copyright for this article is retained by the author(s), with first publication rights granted to the journal.

This is an open-access article distributed under the terms and conditions of the Creative Commons Attribution license (http://creativecommons.org/licenses/by/4.0/). 